\title{
Attitude of Midlands State University Students towards Male Circumcision as A Way of Reducing Hiv Transmission.
}

\author{
Mtemeri Jeofrey, Samson Zivanai \& Shoniwa Gwendoline \\ Great Zimbabwe University Dept of Psychology and HR
}

\begin{abstract}
There is overwhelming evidence that male circumcision reduces the transmission of HIV in heterosexual males. This study assesses the attitude of university students towards male circumcision (MC). The study targeted both the male and female students at Midlands State University. A random sampling technique was used to select the participants. Six hundred and sixteen students (408 males and 208 females) from all the university faculties participated in the study. The study established that in principle the students have a generally more positive attitude towards MC as evidenced by $84 \%$ of the participants who were in favour of it. However of all the male participants who took part in the study only 20\% were circumcised. Half of the remaining $80 \%$ were prepared to get circumcised. One quarter of the remainder needed time to think about it and the other quarter were against it. One hundred percent of the participants cited fear of pain as the most probable hindrance to MC. Eighty percent cited reduction in sexual pleasure as another problem to MC. The overall conclusion drawn from this study was that circumcision could be the way forward in the reduction of HIV transmission in heterosexual partners despite the negative issues that are associated with it. This study also established that as long as MC is correlated with HIV/AIDS it will take long to gain the ground since people still have the fear and stigma associated with HIV testing. However this study recommends that male circumcision be tackled as an independent entity without being associated with HIV/AIDS and that testing for HIV should not be a precondition for circumcision.
\end{abstract}

Key Words: Male circumcision, HIV, university students, attitude, heterosexual

\section{Introduction}

Despite the decrease of HIV/AIDS in Zimbabwe from approximately $26.5 \%$ in 2001 to $15.6 \%$ in 2007 , the HIV statistics are still very high. According to the National Aids Council (NAC) (2002) in Zimbabwe two transmission mechanisms account for most new HIV infection in the country. Eighty-four percent is through sexual contact and $15 \%$ is through mother to child transmission. Adolescents and young adults account for most new HIV infections in Zimbabwe (NAC 2002).

Male circumcision (MC) is a new phenomenon in the fighting against the spread of HIV. The government of Zimbabwe through the Ministry of Health and Child Welfare is advocating for male circumcision as a way of reducing the transmission of HIV. Male circumcision is defined as the surgical removal of some or all the foreskin from the penis, (WHO 2012, CDC 2008). Male circumcision is an effective strategy to reduce the risk of HIV acquisition in heterosexual men (Bailey et al 2007, Gray et al 2007). Male circumcision reduces the risk of heterosexually acquired HIV infection in men by 51- 60\% (WHO 2012, Tobian \& Gray 2011). This is not a mean figure to ignore given the high percentages of HIV infection in the sub-Saharan Africa. By 2006 an estimated 39, 5 million people were living with HIV and 60\% of them in sub Saharan Africa (UNAIDS 2003, WHO/UNAIDS 2007). Prevention becomes a priority in response to the pandemic. Male circumcision is one of the preventive measures. Lack of circumcision has also been associated with sexually transmitted genital ulcer, cervical cancer in women with uncircumcised partners and penile cancer (Alanis and Lucidi; 2004). If all these are associated with lack of circumcision then circumcision becomes paramount and a priority.

In 2006 United States National Institute of Health announced the two trials assessing the male circumcision on HIV risk areas and realised that it reduces the infection by $53 \%$. These findings raised lots of eyebrows within the academic circles, as other people questioned the ecological and racial issues. However other studies that were carried out in South Africa in 2005 and in Kenya and Uganda 2006 recorded similar results $60 \%$ and $51 \%$ respectively.

In Zimbabwe male circumcision is a new phenomenon although there are fragments of the population that practice male circumcision such as the Shangani, Remba and the Tonga. This background could be a matter of concern as people might resist or take long to understand. A stakeholder consultation meeting on male circumcision coordinated by the Ministry of Health and Child welfare was held in 2007 and recommended that circumcising men especially those between the ages of 20-29 years could lead to the greater reduction in HIV infection. HIV incidence could be reduced by $25-35 \%$ if $50 \%$ of the men were circumcised. This study targeted 
the university students since the majority of students are within the above mentioned age limit. The age group is also within the most vulnerable group in terms of HIV infection.

Ethical issues were raised as barriers to male circumcision (Quinn 2006). Most Zimbabweans are religious people and might shun circumcision. Christians for example would see circumcision as sin as they believe in abstinence and have no fear of contracting HIV as they are doing without condoms. Some might fear the side effects of circumcision. Westercamp et al (2012) cited the following; beliefs that circumcision was not part of local culture, the perception of long healing period following the procedure, the lack of specific impetus to seek out services and the general fear of pain associated with becoming circumcised. However, according to Alanis and Lucidi (2004) male circumcision is seen as having little complications which include pain and mild bleeding depending on the method used and the person who carried out the operation. The study looked at the attitude and beliefs of university students towards male circumcision.

Students in Zimbabwe are said to be sexually active from as early as their teenage years and gaining momentum as they approach their 20s (Martin and Alexander 2006). A study carried out in Zimbabwe by Shumba et al (2011) concurred with Martin and Alexander(2006) when they said there was high level of sexual activity among young men and women in the university. Shumba et al (2011) also purport that in spite of the high levels of knowledge about HIV/AIDS, high levels of concurrent sexual relationships were prevalent among students in Zimbabwe hence the need for this study to assess the attitude of students towards male circumcision.

\section{Methodology}

This cross-sectional quantitative survey approach was used to collect data from university students. Quantitative research uses numbers and numerical values to summarize the whole study and to look at relationship between variable and participants of the research (Neil 2007). Results from quantitative surveys can be represented in the form of tables, graphs and charts, which can often communicate very efficiently with people under severe time shortage and information overload. It focuses on the measurement and amount of characteristics and behaviour (Thomas 2003). A random sampling technique was used to select the participants. A random sample is one where the researcher ensures that each member of the population has an equal probability of being selected. The researcher hand delivered the questionnaires to the students who were on the campus on the day. Seven hundred questionnaires were distributed and a total of 616 were satisfactorily completed and returned which was $89.43 \% \%$ response rate. Four hundred and eight $(66.2 \%)$ were males and $208(33.8 \%)$ were females.

1. Table 1: Age of participants

\begin{tabular}{|l|l|l|l|l|l|}
\hline Female & Frequency & Percentage & Male & Frequency & Percentage \\
\hline Below 24 & 137 & 65.87 & Below 24 & 192 & 47.06 \\
\hline $\mathbf{2 5 - 3 0}$ & 71 & 34.13 & $\mathbf{2 5 - 3 0}$ & 216 & 52.94 \\
\hline 30 and above & 0 & 0 & $\mathbf{3 0}$ and above & 0 & 0 \\
\hline Total & 208 & Total & 408 & 100 \\
\hline
\end{tabular}

Most of the female participants $65.87 \%$ were below the age of 24 and most of the male participants were above 24 but below 30 as indicated by table 2 . According to WHO (2007) this age group is the one that is at higher risk of contracting HIV.

2. Table 2: Participants by faculty

\begin{tabular}{|l|c|c|}
\hline Faculty & Frequency & Percentage \\
\hline Arts & 96 & 15.58 \\
\hline Commerce & 15 & 2.44 \\
\hline Law & 9 & 1.46 \\
\hline Natural Resources & 48 & 7.79 \\
\hline Science & 57 & 9.25 \\
\hline Social Sciences & 391 & 63.48 \\
\hline Total & 616 & 100 \\
\hline
\end{tabular}

All the faculties in the university were represented accept the faculty of education which has most of its students on block release. However the representation was not fairly represented with faculty of social sciences dominating. Since the sampling was random the difference in representation is really difficult to explain. However faculties of law and commerce had few participants since the faculties are housed at a different site off the main campus where the selection of participants was done. The difference in representation will not have the significant influence to the results. 


\section{Results and Discussions}

\section{Table 3: Responses on whether HIV is still a topical issue}

\begin{tabular}{|l|l|l|}
\hline HIV still a topical issue & Frequency & Percentage \\
\hline Strongly agree & 376 & 61.04 \\
\hline Agree & 151 & 24.51 \\
\hline Disagree & 57 & 9.26 \\
\hline Strongly disagree & 32 & 5.19 \\
\hline Total & 616 & 100 \\
\hline
\end{tabular}

$\mathrm{N}=616$

Table 3 indicates that HIV is still a topical issue. Over eighty percent of the participants either agree or strongly that $\mathrm{HIV}$ is still an issue that requires attention. However there was a significant percentage although small that felt HIV was no longer an issue. Three quarters of those who were negative about circumcision were those who felt that HIV was no longer an issue anymore. Statistics show that HIV cases are still high especially in the sub Saharan Africa (Mateveke, Mashoko and Mateveke 2012.) Zimbabwe is among the leading nations in SADC in terms of HIV transmission (WHO 2007).

\section{Awareness of male circumcision}

Ninety-seven percent of the participants were generally aware of male circumcision. But students did not have details pertaining to MC. Students failed to give more information about MC. The information that they have concerning MC was that provided on the posters that are displayed in the university campus and also from the public media. No officials from the Ministry of Health and Child welfare have ever been to the university and talked about the benefits of MC. Students have haze information about MC. Sixty percent of the participants have read from newspapers while $30 \%$ have heard people talking about it in public places and the remaining $10 \%$ got the information from other media. Most of those who have been circumcised were on religious beliefs and only 5\% of those circumcised was as a result of the campaign done under the Ministry of Health and Child welfare.

\section{Table 4: Male circumcision reduces HIV infection}

\begin{tabular}{|l|l|l|}
\hline Male circumcision reduces HIV transmission & Frequency & Percentage \\
\hline Strongly agree & 271 & 43.99 \\
\hline Agree & 243 & 39.45 \\
\hline Disagree & 46 & 7.47 \\
\hline Strongly disagree & 56 & 9.09 \\
\hline Total & 616 & 100 \\
\hline
\end{tabular}

$\mathrm{N}=616$

Over $83 \%$ of the participants either agreed or strongly agreed that male circumcision could reduce the transmission of HIV in Heterosexual partners. This is quite positive. However eighty percent of the respondents were not circumcised. Only $20 \%$ were circumcised. This is in line with the WHO statistics that were provided in 2007 although their figure of $15 \%$ is slightly lower (WHO 2007). Many other SADC countries such as Botswana, Swaziland, Namibia and Zambia, have similar ratings (WHO 2007). These countries have high HIV cases and according to WHO/UNAIDS guidelines such countries are recommended for male circumcision since they have high HIV prevalence. Other countries such as Malawi, South Africa, Lesotho, Mozambique, Angola and Madagascar have higher circumcision statistics as compared to Zimbabwe (WHO 2007). An estimated 2.1 million adults were newly infected with HIV in 2007 of whom two thirds live in Sub Saharan Africa (Ngoji 2010.) High prevalence countries include Botswana, Lesotho, Malawi, Mozambique, Namibia, Swaziland, Zambia, South Africa and Zimbabwe (WHO 2007). Most of these countries have low statistics of male circumcision. When those who were not circumcised asked whether they had an intention of getting circumcised in the near future, mixed reactions were noted. Fifty percent were prepared as another $50 \%$ were composed of those who were not prepared and those who were not sure. These results are consistent with Anderson and Crockcroft (2012). According to Quinn (2006) studies in Kenya, South Africa, Uganda, Botswana, Haiti, Tanzania, Zambia and Zimbabwe reported acceptability rates of 48\%-85\%. Juxtaposing the figures of this study and Quinn's study Zimbabweans are within Quinn's acceptability rates. Perhaps the participants that were used could play a pivotal role. Quinn's assertion does not tell whether it was adults or the youth or mixed but this study only looked at the youth at Midlands State University.

Thirty point nine percent have either a friend or a relative or both who were circumcised. This implies that circumcision is being pursued as an option for reducing the transmission of HIV or for other reasons. However the bigger percentage do not have any one close to them who was circumcised. This figure implies resistance or lack of knowledge with regards to male circumcision. 


\section{Strengths and drawbacks about male circumcision}

Ninety percent of the uncircumcised and $100 \%$ of the women who participated in the study cited pain as the deterrent of circumcision. Other problems that were identified were that people would take long before they embark to sexual intercourse whilst they wait for wounds to heal. More than $50 \%$ felt that cutting of the foreskin would affect their sexual pleasure. According to Auvert et al (2006) however the cutting of the foreskin would actually increase the sexual pleasure. Sixty percent had a feeling that circumcision for the sake of reducing the transmission of HIV would actually increase the rate of transmission since those who have been circumcised would think they have the licence to practice unsafe sex. The participants also cited the strengths of getting circumcised such as the reduction of penile cancer and the hygienic reasons. Thirty percent mentioned male circumcision as a protective measure for HIV prevention. Some male participants held the view that circumcision would affect their masturbation which they see as an efficient way of reducing HIV transmission.

\section{The future of male circumcision}

There future is quite fairly positive although some concerns were raised with regards to male circumcision. The majority of female students were positive about the future of MC in terms of people responding positively to circumcision. However the male students felt that as long as male circumcision is perceived with HIV the people would perceive it negatively. Participants also noted that if MC is not well explained to people it might worsen the situation since those who indicated the need to be circumcised were doing so in order to stop using condoms like what was reflected by Tapiwa Gomo's article in the Newsday 2012. Although Gomo's article questioned the integrity of male circumcision as a way of reducing the transmission of HIV he pointed out that people might take it as an invisible condom. In other words people might stop using condoms believing that circumcised men would no longer contract HIV. On the question where participants were asked about whether they were ready to know their HIV status $80 \%$ were not ready. The students would not go for circumcision since HIV testing is a pre requisite for circumcision. This is evidenced by the National Aids Council statistics of 2004 where 15\% females and 7\% males (youth) have been tested for HIV. The figures explain the resistance by the youth towards HIV testing. In other words if the pre requisite for circumcision is testing for HIV then the same resistance will be experienced.

\section{Conclusions and Recommendations}

Students have a fairly positive attitude towards male circumcision as evidenced by $70 \%$ of the participants who felt that male circumcision could be the answer to the reduction of HIV transmission. Hundred percent of the female participants were advocating for their partners to be circumcised. Fifty percent of the male participants were positive that they would go for circumcision, with another quarter of the remainder showing that they needed time to think over it. The participants noted that MC improves on the hygiene of those who have been circumcised and also the reduction in penile cancer. Fear of pain, profuse bleeding and reduction in sexual pleasure were identified as the factors that might cause poor response to MC. Apparently as long as MC had to be correlated with HIV it would take longer for people to go for it and as long as HIV testing was a pre requisite for $\mathrm{MC}$ then it would see very few people supporting it since most of the people do not want to know their HIV status. However if students are educated about MC they are likely to support the idea. This study therefore recommends that MC be taken as an independent entity without linking it to HIV. The study further recommends that the ministry of health and child welfare hold public lectures at institutions of higher learning on the benefits of male circumcision. It is also suggested that MC should not be used as the only way of reducing the transmission of HIV but together with other existing methods. It is also recommended that HIV testing as a precondition for circumcision be removed.

\section{References}

[1]. Alanis, M.C. and Lucid, R.S. (2004.) Neonatal Circumcision: A review of the world's oldest and most controversial operation. Obstet Gynecol;59(5):379-95

[2]. Andersson, N andCockcroft, A. (2012). Male circumcision attitudes to HIV prevention and HIV status: A cross sectional study in Botswana, Namibia and Swaziland. AIDS Care 27 (3): 301-309

[3]. Auvert, B.,Taijaard, D., Lagarde, E., Sobngwi-Tambekou, J., Sitta, R. and Puren, A. (2006). A randomized controlled intervention trial of male circumcision for reduction of HIV infection risk: the ANRS 1265 Trial PLos Med 2005

[4]. Bailey, R., Moses, S., Parker, C., Agot, K., Maclean, I., Krieger, J. and Ndinya, J. (2007). Male circumcision for reduction of HIV infectioin risk: The ANRS 1265 trial PloS Medecine 2, 1112-1122.

[5]. Gray, R., Kigozi, G., Serwadda, D., Makumbi, F., Watya, S., Nalugoda, F. and Wawer, M. J. (2007). Male circumcision for HIV prevention in men in Rakai Uganda: A Randomised trial Lancet, 369 657-666

[6]. Gomo, T. (2012) Male Circumcision. Newsday 15 April 2012 issue, Harare

[7]. Martin, L. and Alexander, P. (2006). Reeponses to HIV/AIDS in South Africa's Tertiary Institutions: Policy Practice and short comings for Sociological Research. Rand Afrikaans University http:/www.uj.ac.zw accessed 28 May 2012

[8]. Mateveke, P., Mashoko, D. And Mateveke A. (2012). Perceptions of people towards male circumcision as a technical method to reduce HIV and AIDS infection in Masvingo District of Zimbabwe. Journal of AIDS and HIV Research 4 (11):284-255

[9]. National Aids Council (2004). The HIV/Aids Epidemic in Zimbabwe 
[10]. Neil, J. (2007). Qualitative versus Quantitative Research: Key points in a classic Debate. http://www.wilderdom.com (Accessed 6 June 2012)

[11]. Ngoji, T. K. (2010). Knowledge, attitude and practices of male circumcision for HIV prevention among voluntary counselling and testing clients in Onandjokwe District Hospital. Namibia. Unpublished.

[12]. Shumba, A., Mapfumo, J and Chademana, J. (2011). The Prevalence of Concurrent Sexual Partnerships among Students in Institutions of Higher Education in Zimbabwe. http:/www.krepublishers.com. Accessed 28May 2012.

[13]. Quinn, T.C. (2006). Circumcision and HIV Transmission: The cutting Edge USA, Baltimore.

[14]. Thomas, R. M. (2003). Building quantitative and qualitative Research Methods in theses and dissertation. USA Corwin Press

[15]. Tobian, A. A. R. And Gray, R. H. (2011.) The Medical Benefits of Male Circumcision. JAMA 2011;306(13):1479-1480

[16]. UNAIDS (2003). Male circumcision current epidemiological and field evidence. Program and policy implementation for HIV prevention and reproductive health, conference report. Washington DC.

[17]. Westercamp, M., Agot, K.W., Ndinya-Achola, J. and Bailey, R.C. (2012). Circumcision preference among women and uncircumcised men prior to scale up male circumcision for HIV prevention in Kisumu Kenya. Aids Care Feb Vol 24 issue 2

[18]. WHO 2012 HIV/AIDS: Male Circumcision

[19]. WHO/ UNAIDS (2007). Global trends and determinants of prevalence, safety and acceptability. UNAIDS/07.290E/JC 1320E 